\title{
Operating room fire using an alcohol-based skin preparation but without electrocautery
}

\author{
Jong Bun Kim, MD · Hyun Ju Jung, MD • \\ Kyong Shil Im, MD
}

Received: 4 December 2012/ Accepted: 14 January 2013/Published online: 24 January 2013

(C) Canadian Anesthesiologists' Society 2013

\section{To the Editor,}

An operating room fire is rare but a well-known hazard that can result in significant patient morbidity. ${ }^{1}$ Due to their well-established antimicrobial properties, alcohol-based skin preparations are commonly used in the operating room despite their known flammability. The risk of an operating room fire with alcohol-based prep solutions is greatest in an oxygen-enriched atmosphere and the use of electrocautery as the ignition source.

We report the occurrence of an operating room fire while using an alcohol-based skin preparation but without the use of electrocautery.

An otherwise healthy 46-yr-old female patient was admitted to our institution for adhesiolysis of a flexion in her right third finger. She preferred general anesthesia. After routine monitors were applied and prior to induction of anesthesia, the patient's lungs were preoxygenated with $100 \%$ oxygen at a flow rate of $5 \mathrm{~L} \cdot \mathrm{min}^{-1}$. Anesthesia was induced with propofol $100 \mathrm{mg} i v$, lidocaine $40 \mathrm{mg} i v$, fentanyl $100 \mu \mathrm{g} i v$, and rocuronium $30 \mathrm{mg} i v$, followed by tracheal intubation. Anesthesia was maintained with 1-2 vol\% of sevoflurane, with an oxygen to nitrous oxide ratio of 1:1 administered at a fresh gas flow rate of $3.0 \mathrm{~L} \cdot \mathrm{min}^{-1}$.

The patient was positioned supine on an operating room table with the affected hand placed on a hand surgery table that was well padded to prevent pressure sores or contusion to the ulnar nerve. An 18-in pneumatic tourniquet was applied to the patient's right upper arm and a cotton drape was placed on the hand surgery table. The patient's right arm was then prepped

J. B. Kim, MD · H. J. Jung, MD · K. S. Im, MD ( $\varangle)$ Department of Anesthesiology and Pain Medicine, College of Medicine, The Catholic University of Korea, Uijeongbu St Mary's Hospital, Uijeungbu-City, Gyeonggi-do, Korea e-mail: idonga@catholic.ac.kr with an $83 \%$ ethyl alcohol solution (Green Ethyl Alcohol Solution $0.83 \mathrm{ml} / \mathrm{ml} \AA$, Green Pharm, Korea). At this point, a fire suddenly ignited over the patient's right arm. The fire was extinguished immediately with a wet cotton drape, and water and ice water were used to cool the wound. The patient's right forearm became slightly swollen and red, and two small-sized blisters formed. The Safety Incident Management Committee investigated the cause of the fire. The surgeon explained the burn incident to the patient's family, obtained their informed consent, and then performed the adhesiolysis using the finger tourniquet.

During the investigation into the cause of the fire, no electrical short circuit was found around the patient or in the patient monitoring devices. The fire was considered to have been caused by pooling of the alcohol-based skin preparation fluid underneath the cotton drape on the hand surgery table. This produced alcohol vapour that was ignited by a static spark.

Operating room fires from alcohol-based skin preparations usually occur in an oxygen-enriched atmosphere and are mainly associated with the use of electrocautery; however, ethyl alcohol is known to ignite and burn in room air (21\% oxygen). A surface wiped down with alcohol requires only a single spark at room air oxygen concentrations to ignite. ${ }^{2}$ In this case, the operating room fire occurred during alcoholbased skin preparation without the use of electrocautery. Therefore, special precautions are necessary when alcoholbased skin preparations are used. The Emergency Care Research Institute has recommended that alcohol-based skin preparation solutions should not be allowed to pool and should be dry or dried before using electrocautery. ${ }^{3}$

In conclusion, the likelihood of fire can be reduced with awareness of the risk and by using simple prevention measures in every case. Anesthesiologists have a role to 
play in minimizing the risk of fire and should appreciate that an operating room fire may occur with alcohol-based skin preparations without the use of electrocautery as the ignition source. Efforts should be made to prevent pooling of the alcohol-based skin preparation and to minimize excess application of solution during the preparation process. Finally, solution-soaked drapes in the operative field should be removed immediately.

Conflicts of interest None declared.

\section{References}

1. Haith LR Jr, Santavasi W, Shapiro TK, et al. Burn center management of operating room fire injuries. J Burn Care Res 2012; 33: 649-53.

2. Rinder CS. Fire safety in the operating room. Curr Opin Anaesthesiol 2008; 21: 790-5.

3. ECRI Institute. New clinical guide to surgical fire prevention. Patients can catch fire-here's how to keep them safer. Health Devices 2009; 38: 314-32. 